\title{
Polyaniline nanofibres as templates for the covalent immobilisation of biomolecules
}

Emer Lahiff ${ }^{\mathrm{a}, 1}$, Carol Lynam ${ }^{\mathrm{b}, 1,{ }^{*}}$, Niamh Gilmartin $^{\mathrm{b}}$, Dermot Diamond ${ }^{\mathrm{a}}$ and Richard O’Kennedy ${ }^{\mathrm{b}}$ ${ }^{\mathrm{a} C L A R I T Y: ~ T h e ~ C e n t r e ~ f o r ~ S e n s o r ~ W e b ~ T e c h n o l o g i e s, ~}$ National Centre for Sensor Research, Dublin City University, Dublin 9, Ireland.

\author{
${ }^{\mathrm{b}}$ School of Biotechnology and Biomedical Diagnostics Institute, \\ National Centre for Sensor Research, \\ Dublin City University, \\ Dublin 9, Ireland.
}

\footnotetext{
* Corresponding author at: School of Biotechnology and Biomedical Diagnostics Institute, National Centre for Sensor Research, Dublin City University, Dublin 9, Ireland Telephone: $+353-1-7007717$

Fax: $+353-1-7006558$

E-mail address: Carol.Lynam@dcu.ie

${ }^{1}$ EL and CL contributed equally
} 


\begin{abstract}
The attachment of antibodies onto polyaniline nanofibres using covalent chemistry was investigated for the first time. Polyaniline nanofibres were functionalised post-polymerisation to attach either amide or carboxylic acid side-groups. These templates could then be further modified to attach antibodies, specifically in this instance mouse immunoglobulin $G$ (IgG). The resultant conjugates were characterised using a variety of techniques including infrared, UVvisible and Raman spectroscopy. Conjugates were then used to detect secondary antibodies (antiIgG). Results from enzyme-linked immunoassay studies indicate successful binding of the antibody to the polyaniline nanofibres. Carboxyl functionalised polyaniline nanofibres are shown in particular to decrease non-specific binding in the immunoassay. Direct electrical communication between polyaniline nanofibres covalently linked to peroxidase-labelled antibodies was observed during cyclic voltammetry, which demonstrates their potential for further development as nano-dimensional immunosensors.
\end{abstract}

Keywords: polyaniline nanofibers, conducting polymer functionalization, antibody conjugation, immunoassay 


\section{Introduction}

Conducting polymers combine the advantages of polymers (being lightweight, inexpensive and easily processed) with the ability to transport charge [1]. Their unique combination of physical, optical and electrical properties, has led to considerable interest in their use as platforms for a wide variety of applications. Examples of conducting polymers used in applications encompassing electrochromic devices, printable electronics and photochromics include polythiophene, polypyrrole and polyaniline $[2,3,4]$. Polyaniline (PAni) has been previously used as a mediator in biosensor applications, due to its inherent electro-activity, favourable charge storage stability and ease of preparation [5,6,7]. Interfacing biomolecules with conducting polymers is a logical step in order to accomplish bio-composite materials which can be used for controlling stimuli-responsive actions involved in drug release, bio-feedback devices, neural implants and artificial muscles [8].

Nanodimensional PAni can be readily prepared, exhibiting markedly improved properties from those of the bulk materials, including increased surface area and sharp switching [9]. The properties unique to one dimensional nanostructures such as nanowires, nanotubes and nanofibres have been the focus of much research, partly due to the promise associated with nanoscale devices for sensors and electronics. For example Virji et al. [9] howed how PAni nanofibre films have far superior performance in both sensor sensitivity and response time in comparison to their bulk counterparts. This is due to faster gas diffusion, enabled by the porous high-surface area nanofibrillar film structure. 
Recently, monolithic microstructures from nanofibers of PAni have been reported [10]. Since the porous properties of monolithic polymers can be easily tuned, monolithic capillary columns have encountered wide interest for applications in capillary electrochromatography, for example functionalised monoliths have been used in protein analysis [11]. Using a capillary coated with polyaniline achieved the separation of the end products of glycosylation [12]. Relative to packed columns, monoliths have the advantages of preparation simplicity and availability for surface modification $[13,14]$. The large surface area of monolithic beds enables a relatively high sample loading capacity. The attachment of proteins to affinity columns have seen use in immunopurification, [15] and the detection of selected analytes by chromatographic immunoassays [16].

The attachment of biomolecules to conducting polymer nanostructures means that bio-active functionalities are anchored to a redox active nano-dimensional system. The nanostructured form of PAni offers a very large surface-to-volume ratio thus facilitating the immobilisation of a greater number of biomolecules, and an enhancement of sensor sensitivity and response times $[9,17]$. One of the most common methods for immobilising biomolecules onto surfaces achieved either physically or by electrochemical techniques, is adsorption [18]. The latter is achieved by applying a potential to the electrode surface, which enhances electrostatic interactions and therefore immobilisation [10]. Using adsorption as the method of immobilisation however has the disadvantage that the biomolecule can easily desorb from the surface during use. Conversely, covalent attachment of biomolecules to nanomaterial surfaces ensures sufficient immobilisation without leaching of the biomolecule from the substrate surface during use [19]. 
The authors have recently reported the successful post-synthesis functionalisation of PAni nanofibres with mercaptoundecanoic acid and cysteamine; thereby incorporating functional handles $\left(\mathrm{COOH}\right.$ and $\left.\mathrm{NH}_{2}\right)$ which allow for further derivatisation of the polymer [20,21]. Post functionalisation, PAni maintains its nano-morphology and ability to switch optical, electrical and electrochemical properties in response to its immediate chemical environment. In this paper, we describe for the first time how PAni nanofibres modified with either carboxyl or amino terminated chains allow for a one step covalent derivatisation of the polymer with biomolecules (in particular we demonstrate the technique for antibodies). Biomolecule immobilisation onto electrode surfaces is of importance for the development of enzyme-catalysed biofuel cells, amperometric biosensors and other biotechnological applications. Here we report a 'generic' approach for immobilisation. PAni-antibody conjugates are of interest as they are low cost and easily scalable. The polyaniline serves as an immobilisation matrix and also plays an active role in transduction. Alternatively these materials could find application as solid phases in affinity monolithic micro-columns for protein separation. 


\section{Experimental Procedures}

2.1 Chemicals: Aniline (BDH), $\mathrm{HCl}$ (Fisher Scientific), ammonium peroxydisulfate (Aldrich), mercaptoundecanoic acid (Aldrich), mercaptopropionic acid (Aldrich), cysteamine (Aldrich) and pH 4 buffer tablets (Fluka) were used. The aniline monomer was purified by vacuum distillation before use. Mouse immunoglobulin G (IgG) (Sigma), anti-mouse IgG labelled with horse radish peroxidase (derived from goat, Sigma), 3,3',5,5'-tetramethylbenzidine dihydrochloride (TMB, Sigma) were used as supplied.

2.2 Nanofibre Synthesis: Polyaniline nanofibres were synthesised, under ambient conditions, by interfacial polymerisation between an aqueous and an organic layer, as reported previously [20]. The product was purified by centrifugation ( $4000 \mathrm{rpm} / 5 \mathrm{~min} / 3$ cycles) and suspended as a colloid in deionised water. Fibres were modified with mercaptoundecanoic acid $\left(\mathrm{HS}\left(\mathrm{CH}_{2}\right)_{10} \mathrm{COOH}\right)$, mercaptopropionic acid $\left(\mathrm{HS}\left(\mathrm{CH}_{2}\right)_{2} \mathrm{COOH}\right)$ or cysteamine $\left(\mathrm{HS}\left(\mathrm{CH}_{2}\right)_{2} \mathrm{NH}_{2}\right)$, by refluxing at 100 ${ }^{\circ} \mathrm{C}$ for 2 hours in an aqueous $\mathrm{pH} 4$ buffer. Four sets of fibres were functionalised; two with cysteamine $(0.1 \mathrm{mmol}$ and $0.3 \mathrm{mmol})$ and two with $0.1 \mathrm{mmol}$ carboxyl groups with different spacer lengths $\left(\mathrm{C}_{10}\right.$ and $\left.\mathrm{C}_{2}\right)$. All experiments were carried out under identical conditions using $\sim 45 \mathrm{mg}$ PAni. The product was purified by centrifugation (4000 $\mathrm{rpm} / 5 \mathrm{~min} / 3$ cycles) and resuspended as a colloid in deionised water.

2.3 Covalent Antibody Immobilisation onto PAni: Briefly, $100 \mu \mathrm{l}$ of mouse IgG, at a concentration of $0.1 \mathrm{mg} / \mathrm{ml}$ was added to $1 \mathrm{ml}$ of the PAni nanofibre dispersions $(0.2 \mathrm{mg} / \mathrm{ml})$ for 1 hour with shaking ( $200 \mathrm{rpm}$ ) at $37^{\circ} \mathrm{C}$. Antibodies were covalently immobilised by the addition of $4 \mathrm{mg}$ ethyl diaminocarbodiimide (EDC), the zero length crosslinker, to the dispersion. The 
PAni-IgG mixture was centrifuged and washed in distilled water 3 times. Any remaining unreacted sites on the nanofibres were blocked with 5 wt. \% milk marvel and incubated overnight at $4{ }^{\circ} \mathrm{C}$. The PAni-IgG mixture was then centrifuged (10 min at $\left.4000 \mathrm{rpm}\right)$ and washed 3 times with distilled water. Anti-mouse IgG labelled with horse radish peroxidise (HRP) was diluted 1 in 1000 in $1 \%(\mathrm{w} / \mathrm{v}$ ) milk marvel/PBS to give a final concentration of $0.6 \mu \mathrm{g} / \mathrm{ml}$ and 1 $\mathrm{ml}$ of this solution was added to the PAni-IgG pellet, re-dispersed and incubated at $37{ }^{\circ} \mathrm{C}$ for one hour. The PAni mixture was then centrifuged (10 min at $4000 \mathrm{rpm})$ and washed a further 3 times with water and the PAni pellet re-suspended in $0.5 \mathrm{ml}$ water.

2.4 Antibody Detection: HRP-labelled antibodies were detected using the 3,3',5,5'tetramethylbenzidine dihydrochloride (TMB) assay prepared as per the manufacturer's instructions. $200 \mu \mathrm{l}$ of TMB solution was added to $250 \mu \mathrm{l}$ of the antibody-labelled PAni solution and incubated in the dark at room temperature for $10 \mathrm{~min}$. This PAni-TMB dispersion was then centrifuged $(10 \mathrm{~min}$ at $4000 \mathrm{rpm})$ and $50 \mu \mathrm{l}$ of the supernatant was added to a microtitre well. The reaction was stopped by the addition of $50 \mu \mathrm{l}$ of $10 \%(\mathrm{v} / \mathrm{v}) \mathrm{HCl}$ and the absorbance was read at $450 \mathrm{~nm} .10 \mu \mathrm{l}$ of each PAni and PAni/Ab-HRP suspension was cast as a film onto clean glassy carbon electrodes and used as the working electrode in cyclic voltammetry.

2.5 Characterisation: Covalent bonding of side-chains to PAni nanofibres was investigated using Fourier Transform infrared spectra (FTIR) recorded in transmission mode from 400 to $4000 \mathrm{~cm}^{-}$ ${ }^{1}$, for 100 repeat scans, with a resolution of $8 \mathrm{~cm}^{-1}$ and at $1 \mathrm{~cm}^{-1}$ intervals on a Perkin Elmer Spectrum GX FTIR. Samples were dried under vacuum at $50{ }^{\circ} \mathrm{C}$ for 4 hours prior to FTIR and then mixed with dried KBr. Dedoped samples were also analysed using solid state nuclear 
magnetic resonance (SSNMR). ${ }^{13} \mathrm{C}$ spectra were obtained using a Varian VNMRS spectrometer operating at $100.56 \mathrm{MHz}$ for carbon, and spectra are referenced to tetramethylsilane. Thermal Gravimetric Analysis (TGA) decomposition curves were obtained using a Mettler-Toledo TGA/SDTA851. Samples were heated from $25-700{ }^{\circ} \mathrm{C}$ at $10{ }^{\circ} \mathrm{C} /$ minute under nitrogen. Nanofibres were coated with $10 \mathrm{~nm} \mathrm{Au} / \mathrm{Pd}$ and imaged using field emission scanning electron microscopy (FESEM) at an accelerating voltage of $20 \mathrm{kV}$ on a S-4300 Hitachi system. Raman spectroscopy was carried out on an Avalon $785 \mathrm{~nm}$ Raman spectrometer at $2 \mathrm{~cm}^{-1}$ resolution, 3 seconds per scan and 10-20 collections. A $785 \mathrm{~nm}$ laser line was used as it can detect both doped and de-doped PAni features. UV-vis spectroscopy was carried out on a Perkin Elmer UV-vis NIR Lambda 900 Spectrometer at $1 \mathrm{~nm}$ resolution. Characterisation of the samples by enzyme assay was obtained using a Tecan Sunrise microplate reader. Absorbance readings were taken at a wavelength of $450 \mathrm{~nm}$. Transmission electron microscopy (TEM) analysis was performed using a Jeol 2100 microscope $(200 \mathrm{kV})$. Cyclic voltammetry was performed using an eDAQ ecorder (401) and potentiostat/galvanostat (EA 160) with Chart v5.1.2/EChem v 2.0.2 software (ADInstruments), and a PC computer, in phosphate buffered saline solution (PBS - $0.2 \mathrm{M}, \mathrm{pH}$ 7.4) with $\mathrm{Ag} / \mathrm{AgCl}$ reference electrode and platinum mesh counter electrode. 


\section{Results and Discussion}

\subsection{Preparation and Characterisation of Functionalised PAni Nanofibres}

Polyaniline nanofibres were synthesised by interfacial polymerisation, whereby the aniline monomer was dissolved in toluene and the oxidant (ammonium persulfate) was dissolved in $1 \mathrm{M}$ hydrochloric acid. Polyaniline nanofibres form at the interface between these two solutions and precipitate into the aqueous layer where they can be collected and purified. These nanofibres were then surface modified with either carboxylic acid or amine groups (for details see Table 1). The extent of this functionalisation could be controllably altered [21]. Covalent attachment was verified using Fourier Transform Infrared Spectroscopy (FTIR), where a band centred around $3400 \mathrm{~cm}^{-1}$ reflects attachment of the amide group, and a band at $1700 \mathrm{~cm}^{-1}$ confirms the presence of an acid group (Figure 1). Polymer functionalisation was verified by peak shift and the elimination of thiol bands (Figure 1, supporting information).

Covalent functionalisation was also verified using cross-polarization magic angle spinning solidstate nuclear magnetic resonance (SSNMR). The spectrum obtained for unmodified PAni is consistent with spectra in the literature [22], and predominant ${ }^{13} \mathrm{C}$ peaks appear at $123.84 \mathrm{ppm}$, $156.73 \mathrm{ppm}$ and $137.25 \mathrm{ppm}$ (Figure 2a, Supporting Information). For carboxylic acid functionalised PAni (PAni- $\left.\mathrm{C}_{10} \mathrm{COOH}\right)$ two additional peaks are present, one at $29.4 \mathrm{ppm}$, which can be assigned to the aliphatic carbon chain of the mercaptoundecanoic acid $\left(\mathrm{SH}\left(\mathrm{CH}_{2}\right)_{10} \mathrm{COOH}\right)$ substituent, and the other at $180.3 \mathrm{ppm}$, which can be assigned to the carbon of the carboxylic acid group (Figure 2b, Supporting Information). For cysteamine functionalised PAni (PAni$\mathrm{NH}_{2}$ ), characteristic PAni peaks appear. Unfortunately, the absorbance band of the C-N cysteamine $\left(\mathrm{HS}\left(\mathrm{CH}_{2}\right)_{2} \mathrm{NH}_{2}\right)$ amide is masked by the $\mathrm{C}-\mathrm{N}$ bonds along the PAni backbone, and 
therefore cannot be isolated (Figure 2c, Supporting Information). The SSNMR spectra confirm the formation of PAni-COOH nanofibres, and are consistent with the formation of $\mathrm{PAni}^{-\mathrm{NH}_{2}}$ nanofibres.

Results obtained by thermal gravimetric analysis (TGA) are also consistent with nanofibre functionalisation. These reveal that PAni, $\mathrm{PAni}-\mathrm{C}_{10} \mathrm{COOH}$ and $\mathrm{PAni}-\mathrm{NH}_{2}$ have different decomposition profiles (Figure 2). Unmodified polyaniline decomposes over a temperature range between $300{ }^{\circ} \mathrm{C}$ and $620^{\circ} \mathrm{C}$, while other decomposition peaks outside this temperature range can be attributed to trapped solvent/dopant in the material [21]. In contrast to this, functionalised nanofibres show two significant areas of decomposition. For PAni- $\mathrm{C}_{10} \mathrm{COOH}$ the peak centred at $504{ }^{\circ} \mathrm{C}$ is consistent with a PAni component, while the second peak at $196{ }^{\circ} \mathrm{C}$ is due to a modified PAni- $\mathrm{C}_{10} \mathrm{COOH}$ surface component (ca. $10 \mathrm{wt} \%$ ). In the case of PAni- $\mathrm{NH}_{2} \mathrm{~B}$, decomposition peaks appear at $558{ }^{\circ} \mathrm{C}$ due to the PAni component, while the amide-modified surface component manifests at $184^{\circ} \mathrm{C}$ (ca. 19wt\%). These TGA results are in agreement with previously published data which shows that the degree of nanofibre functionalisation can be controlled for both $\mathrm{PAni}-\mathrm{COOH}$ and $\mathrm{PAni}-\mathrm{NH}_{2}$.

\subsection{Antibody immobilisation}

Covalent immobilisation of antibodies onto functionalised polyaniline (PAni) nanofibres was investigated and involved attachment of antibodies to both carboxyl and amino functionalised PAni nanofibres (Pani-COOH and Pani- $\mathrm{NH}_{2}$ respectively). To determine the effect of chain length on antibody immobilisation, carboxyl functionalised PAni nanofibres with two carbon (PAni- $\left.\left(\mathrm{CH}_{2}\right)_{2}-\mathrm{COOH}\right)$, and ten carbon (PAni- $\left.\left(\mathrm{CH}_{2}\right)_{10}-\mathrm{COOH}\right)$ spacer chains were examined. In 
the case of amine functionalised PAni nanofibres, two different concentrations of cysteamine were used to compare the effect of amino-group density with respect to antibody immobilisation (products from $0.1 \mathrm{mmol}$ and $0.3 \mathrm{mmol}$ cysteamine reactions are denoted $\mathrm{Pani}-\mathrm{C}_{2} \mathrm{NH}_{2} \mathrm{~A}$ and Pani- $\mathrm{C}_{2} \mathrm{NH}_{2} \mathrm{~B}$, respectively, see Table 1).

For the immobilisation, both types of $\mathrm{PAni}-\mathrm{COOH}$ and $\mathrm{PAni}-\mathrm{NH}_{2}$ dispersions were mixed with the primary antibody, mouse immunoglobulin $\mathrm{G}$ ( $\mathrm{IgG})$, and the cross linker ethyl diaminocarbodiimide (EDC). A range of blocking agents were tested (ovalbumin, bovine serum albumin (BSA), Tween 20®, BSA/milk marvel (1:1), milk marvel, gelatin, Super Block®, KLH protein and soya milk) and the results indicate that milk marvel was the most effective blocking agent against non-specific binding (See figure 3, supporting Information). Milk marvel therefore was used for all PAni samples tested. As future work will involve adaptation of this method for a sandwich immunoassay, an unlabelled antibody was immobilised onto the PAni nanofibres.

\subsection{Characterisation of antibody conjugates}

The nanofibre morphology of PAni can be verified using scanning electron microscopy (SEM). Nanofibres synthesised by interfacial polymerisation have a uniform diameter distribution and a high surface area, thus making them ideal for use as a sensing platform. Post-functionalisation, the nanofibre morphology appears essentially unaffected. However, greater aggregation of the nanofibres is observed following antibody immobilisation, which results in an apparently less porous film structure (Figure 3). This is analogous to functionalisation of PAni with carboxyl and amino groups, in that the degree of aggregation scales with the level of functionalisation [20]. Films do however maintain a high surface-to-volume ratio in comparison with bulk PAni. 
The surface topography of the nanofibres appears altered suggesting that the attachment of biomolecules was successful.

Functionalisation affects the delocalised bonding along the PAni polymer backbone, and this can be monitored by analysing spectroscopic changes in the materials (in particular UV-vis and Raman spectra were examined). For UV-vis spectra, a polaron band at $450 \mathrm{~nm}$ with a free carrier tail above $600 \mathrm{~nm}$ indicates that PAni is in the doped (emeraldine salt, therefore conductive) state [23]. For a dedoped (emeraldine base, therefore non-conductive) state these bands disappear and a $\pi-\pi^{*}$ transition band at $341 \mathrm{~nm}$ dominates, with a band at $660 \mathrm{~cm}^{-1}$ due to the quinoid fraction of the PAni backbone [24]. For unmodified PAni in an aqueous environment the material remains in the doped form (Figure 4). However, with functionalised $\mathrm{PAni}-\mathrm{NH}_{2}$ and $\mathrm{PAni}-\mathrm{COOH}$ in an aqueous environment, features of the dedoped state begin to emerge. This is due to the fact that functionalisation disrupts the delocalised $\pi$-system of chemical bonds along the PAni polymer backbone. For PAni-antibody conjugates, further dedoping of the material is observed due to the higher $\mathrm{pH}$ environment that the nanofibres are exposed to during conjugation. Aromatic amino acids associated with antibodies absorb strongly near $280 \mathrm{~nm}$ and a peak corresponding to this is clearly seen for all spectra of the PAni-antibody conjugates. Therefore UV-vis results suggest that antibody functionalisation was successful.

The dedoped state of PAni-antibody conjugates was also reflected in Raman spectra of the material (Figure 4, Supporting Information). Spectra of PAni in the doped conductive state have signature bands between $1300-1400 \mathrm{~cm}^{-1}$, and these are present for PAni- $\mathrm{NH}_{2}$. Strong bands 
between $1400-1500 \mathrm{~cm}^{-1}$ reflect a transition to the dedoped state, and these emerge for the PAni$\mathrm{NH}_{2}$-antibody conjugate.

The electrochemical behaviour of carboxyl- and amino-functionalised PAni nanofibres (without antibodies attached) deposited on glassy carbon electrodes (GCEs) was studied by cyclic voltammetry in $0.2 \mathrm{M} \mathrm{KCl}(\mathrm{pH} 1)$, and the results are shown in Figure 5(a and b). Two pairs of redox peaks centred at approximately +0.20 and $+0.70 \mathrm{~V}$ corresponding to the transformation of leucoemeraldine base to emeraldine salt and emeraldine salt to pernigraniline salt, respectively, can be observed for all PAni nanofibre samples. The presence of covalently bound acid functionalities along the polymer backbone does not appreciably alter the electrochemical behaviour of polyaniline nanofibres. As expected, redox behaviour is similar to that of PAni for low levels of functionalisation. However, increasing the levels of functionalisation, as previously discovered, affects the electrochemical properties of the material and is observed in the case of amino functionalised PAni (Figure 5b). With increasing PAni functionalisation, the numbers of unfunctionalised quinoid rings along the PAni backbone decrease and CV scans show an increased redox pair peak separation. This is caused by higher levels of functionalisation disrupting the delocalised $\pi$-bonding of the polymer network, and hence the oxidation potential of the material.

The electrochemical behaviour of antibody-functionalised PAni nanofibres deposited on GCEs was also studied by cyclic voltammetry in $0.2 \mathrm{M} \mathrm{KCl}(\mathrm{pH} \mathrm{1}$, Figure 5). The presence of conjugated antibodies on the PAni nanofibres caused a shift in the peak potentials of the second redox pair to approximately $+0.55 \mathrm{~V}$. It is known that the second oxidation peak of polyaniline 
moves to a less positive potential with increasing $\mathrm{pH}$. The shift to $+0.55 \mathrm{~V}$ may be due to the presence of conjugated antibodies adjacent to polymer chains, changing the local chemical and hence electrochemical environment of the polymer.

\subsection{Immobilisation of secondary antibodies}

A secondary antibody, anti-mouse IgG labelled with HRP (derived from goat) was used in order to detect the presence of the immobilised primary antibody (Scheme 1). The secondary antibody was incubated with the primary antibody-modified PAni nanofibres. PAni nanofibre antibody conjugates (PAni- $\mathrm{C}_{2} \mathrm{COOH}, \mathrm{PAni}-\mathrm{C}_{10} \mathrm{COOH}, \mathrm{PAni}-\mathrm{NH}_{2} \mathrm{~A}$ and $\mathrm{PAni}-\mathrm{NH}_{2} \mathrm{~B}$ ) were assayed using the colorimetric tetramethylbenzidine (TMB) enzyme assay. The presence of antibodies on PAni nanofibre samples can be confirmed by the TMB assay results (Figure 6). Levels of antibody functionalisation across samples appear broadly similar with the carboxyl functionalised nanofibres exhibiting the least non-specific binding (NSB). In antibody-based assays, the surface has to be treated to minimise non-specific adsorption. NSB controls the background response and often results in a detection limit that is much higher than that defined by the equilibrium constants for antibody-antigen binding events. NSB for the amine-functionalised nanofibres was reduced by increasing the level of nanofibre functionalisation, but not to the level of carboxyl functionalised PAni nanofibres.

Transmission electron microscopy (TEM) images of the PAni-antibody conjugates reveal that the morphology of the PAni nanofibres remains largely unaffected by the antibody conjugation process (Figure 7). TEM imaging, however, is consistent with modification of nanofibre surfaces, as indicated by an apparent increase in surface roughness. For HRP-labelled PAni- 
antibody conjugates, dark spheres on the surface of the nanofibres can be observed, consistent with the size of HRP labels (Figure 7d). EDXS analysis on films of these PAni-antibody conjugates confirms the presence of iron from the metal centre of the HRP enzyme label on the secondary antibody (Figure 5, Supporting Information).

Electrochemical characterisation of PAni nanofibres functionalised with the secondary antibody, HRP-labelled anti-mouse IgG, was carried out in phosphate buffered saline as electrolyte (pH 7.4, to prevent antibody denaturation). Figure 8 shows the cyclic voltammograms obtained from samples drop cast as films on GCEs. Polyaniline typically loses its electroactivity in solutions with increasing $\mathrm{pH}$, as the emeraldine salt is dedoped to form the insulator emeraldine base. As expected, no clear redox responses were observed from PAni control samples without the primary antibody covalently attached. PAni nanofibres without the primary antibody covalently attached are not expected to specifically bind the redox active HRP-labelled anti-mouse IgG. As verified by the TMB assay results, minimal non-specific binding of this protein to the PAni nanofibres is observed.

In contrast, an obvious, stable redox couple (anodic peak $(+0.22 \mathrm{~V})$ and cathodic peak $(+0.09 \mathrm{~V})$ ) was observed for PAni samples functionalised with both primary (mouse IgG) and HRP-labelled secondary antibodies (anti-mouse IgG). This redox couple may be attributed to the iron centre of the HRP enzyme (Figure 8). In a control experiment, an electrode was constructed by drop casting $5 \mu \mathrm{l}$ of carboxy-modified PAni in water onto a glassy carbon electrode and allowing it to dry. Following this, $5 \mu \mathrm{l}$ of a $1 \mathrm{mg} / \mathrm{ml}$ solution of HRP (no primary or seconday antibody) in PBS was drop cast onto the PAni modified GCE. Cyclic voltammetry of this control 
sample in PBS (not shown) exhibited a stable redox couple at approximately $+0.20 \mathrm{~V}$. This confirms that the redox couple obtained with the PAni nanofibres functionalised with HRPlabelled anti-mouse IgG was definitely due to the HRP moiety. These results strongly suggest that direct electron transfer was achieved between the PAni nanofibres and the covalently bioconjugated peroxidase enzymes.

\section{Conclusion}

The covalent attachment of antibodies to conducting polymer nanofibres was successfully demonstrated. Attachment can be achieved using a controllable and relatively simple process, which can easily be scaled up for bulk production. Antibody conjugates can then be used to detect the presence of secondary antibodies. HRP-labelled antibodies can also be attached, thus suggesting potential application in nanostructured immunosensors for point of care detection. For

clinically relevant point of care immunoassays, non-specific adsorption must be minimised, and in particular carboxyl functionalised polyaniline nanofibres were shown to decrease non-specific binding in the immunoassay. This platform could be further developed to attach other enzymes, antibodies and oligonucleotides. Thus providing a material which is if interest for a range of applications including affinity columns for protein separation, biosensors, biofuel cells and bioelectronic systems.

\section{Acknowledgment}

This material is based upon research supported by the Science Foundation Ireland under Grant No. 05/CE3/B754. CL acknowledges the EU Seventh Framework Programme for support in the 
form of a Marie Curie Re-Integration Grant. EL and DD acknowledge SFI 07/CE/I1147 "CLARITY: Centre for Sensor Web Technologies", and Enterprise Ireland PC/2008/0149.

\section{Figure captions:}

Table 1: A summary of modified nanofibres investigated.

Scheme 1. PAni nanofibre modification, where conditions involve (i) thiol reflux, (ii) EDC coupling of primary antibody and (iii) incubation with HRP-labelled secondary antibody.

Figure 1: FTIR spectra for functionalised nanofibres show either a carboxylic acid band at 1700 $\mathrm{cm}^{-1}$ or an amine band at $3400 \mathrm{~cm}^{-1}$.

Figure 2: TGA curves of PAni, $\mathrm{PAni}-\mathrm{COOH}$ and $\mathrm{PAni}-\mathrm{NH}_{2}$ have clearly different profiles (left). Plotting of the differential of TGA curves allows for a clearer interpretation of results (right).

Figure 3. SEM images show high surface area functionalised $\mathrm{PAni}-\mathrm{NH}_{2}$ nanofibres (a-b), and PAni- $\mathrm{NH}_{2}$ antibody conjugates (c-d).

Figure 4. UV-vis spectra of $\mathrm{PAni}-\mathrm{COOH}$ and $\mathrm{PAni}-\mathrm{NH}_{2}$, along with their antibody conjugates (all in aqueous solution). (Spectra have been normalised for clarity).

Figure 5. Cyclic voltammetry carried out in $0.2 \mathrm{M} \mathrm{KCl}(\mathrm{pH} 1)(\mathrm{a}, \mathrm{b})$ as electrolyte at $100 \mathrm{mV} / \mathrm{s}$ scan rate.

Figure 6. Indirect ELISA using Pani-nanofibres immobilised with mouse IgG, an anti-mouse HRP-labelled antibody as a secondary antibody and using the HRP substrate, 3,3',5,5'tetramethylbenzidine (TMB) for detection. Pani-nanofibres not immobilised with antibodies were used as a negative control. 
Figure 7. TEM images show high surface area PAni nanofibres (a and b) and PAni-COOH antibody conjugates (c and d).

Figure 8. Cyclic voltammetry carried out in phosphate buffered saline (pH 7.4) as electrolyte at $100 \mathrm{mV} / \mathrm{s}$ scan rate.

\section{References}

[1] A.G. MacDiarmid, J.C. Chiang, A.F. Richter, A.J. Epstein, Synthetic Met. 18 (1987) 285290.

[2] D.F.Acevedo, J. Balach, C.R. Rivarola, M.C. Miras, C.A. Barbero, Faraday Discussions 131 (2006) 235-252.

[3] C. Barbero, M.C. Miras, B. Schnyder, O. Haas, R. Kotz, J. Mater. Chem. 4 (1994) 17751783.

[4] W.R. Small, F. Masdarolomoor, G.G. Wallace, M. Panhuis, J. Mater. Chem. 17 (2007) 43594361 .

[5] H. Peng, L. Zhang, C. Soeller, J. Travas-Sejdic, Biomaterials 30 (2009) 2132-2148.

[6] H. Peng, C. Soeller, N.A. Vigar, V. Caprio, J. Travas-Sejdic, Biosens. Bioelectron. 22 (2007) 1868-1873.

[7] Z. Wang, S. Liu, P. Wu, C. Cai, Anal. Chem. 81 (2009) 1638-1645.

[8] G. Wallace, G. Spinks, Soft Matter 3 (2007) 665-671.

[9] S.Virji, J.X. Huang, R.B. Kaner, B.H. Weiller, Nano Letters 4 (2004) 491-496.

[10] B. Shedd, C.O. Baker, M. J.Heller, R.B. Kaner, H.T. Hahn, Materials Science and Engineering B 162 (2009) 111-115.

[11] X. Sun, W. Yang, T. Pan, A.T. Woolley, Anal. Chem. 80 (2008) 5126-5130.

[12] P.F.G. de Sa, C. Robb, E. Resende, P. McCarthy, S.C. Yang, P.R. Brown, J.A. Dain, Journal of Capillary Electrophoresis and Microchip Technology 7 (2002) 61-65.

[13] M.J. Benes, D. Horak, F.J. Svec, Sep. Sci. 28 (2005) 1855-1875.

[14] S. Eeltink, F. Svec, Electrophoresis 28 (2007) 137-147. 
[15] S. Anastase-Ravion, Z. Ding, A. Pelle, A.S. Hoffman, D. Letourneur, J. Chromatogr. B 761 (2001) 247-254.

[16] M. Lonnberg, J. Carlsson, J. Chromatogr, A 1127 (2006) 175-182.

[17] S. Virji, J.D. Fowler, C.O. Baker, J.X. Huang, R.B. Kaner, B.H. Weiller, Small 1 (2005) 624-627.

[18] X. Jiang, Q. Xu, S.K.W. Dertinger, A.D. Stroock, T. Fu, G.M. Whitesides, Anal. Chem. 77 (2005) 2338-2347.

[19] A.C. Henry, T.J. Tutt, M. Galloway, Y.Y. Davidson, C.S. McWhorter, S.A. Soper, R.L. McCarley, Anal. Chem. 72 (2000) 5331-5337.

[20] E. Lahiff, T. Woods, W. Blau, G.G. Wallace, D. Diamond, Synthetic Met. 159 (2009) 741748.

[21] E. Lahiff, S. Scarmagnani, B. Schazmann, A. Cafolla, D. Diamond, International Journal of Nanomanufacturing 5 (2010) Nos. $1 / 2$.

[22] S. Kaplan, E.M. Conwell, A.F. Richter, A.G. Macdiarmid, J. Am. Chem. Soc. 110 (1988) 7647-7651.

[23] M. Inoue, F. Medrano, M. Nakamura, M.B. Inoue, Q. Fernando, J. Mater. Chem. 4 (1994) 1811-1814.

[24] T. Yasuda, I. Yamaguchi, T. Yamamoto, J. Mater. Chem. 13 (2003) 2138-2144. 
Table 1.

\begin{tabular}{|c|c|c|c|}
\hline Reaction & Product Difference & Product Name & $\begin{array}{l}\text { Product } \\
\text { Group }\end{array}$ \\
\hline $\begin{array}{c}\text { Pani }+\mathrm{HS}\left(\mathrm{CH}_{2}\right)_{2} \mathrm{COOH} \\
(0.1 \mathrm{mmol}) \\
\text { Pani }+\mathrm{HS}\left(\mathrm{CH}_{2}\right)_{10} \mathrm{COOH} \\
(0.1 \mathrm{mmol})\end{array}$ & $\begin{array}{l}\text { Shorter spacer } \\
\text { Longer spacer }\end{array}$ & $\begin{array}{c}\text { Pani- } \mathrm{C}_{2} \mathrm{COOH} \\
\text { Pani- } \mathrm{C}_{10} \mathrm{COOH}\end{array}$ & Pani-COOH \\
\hline $\begin{array}{c}\text { Pani }+\mathrm{HS}\left(\mathrm{CH}_{2}\right)_{2} \mathrm{NH}_{2} \\
(0.1 \mathrm{mmol}) \\
\text { Pani }+\mathrm{HS}\left(\mathrm{CH}_{2}\right)_{2} \mathrm{NH}_{2} \\
(0.3 \mathrm{mmol})\end{array}$ & $\begin{array}{l}\text { Lower density amines } \\
\text { Higher density amines }\end{array}$ & $\begin{array}{l}\text { Pani- } \mathrm{C}_{2} \mathrm{NH}_{2} \mathrm{~A} \\
\text { Pani- } \mathrm{C}_{2} \mathrm{NH}_{2} \mathrm{~B}\end{array}$ & Pani-NH 2 \\
\hline
\end{tabular}




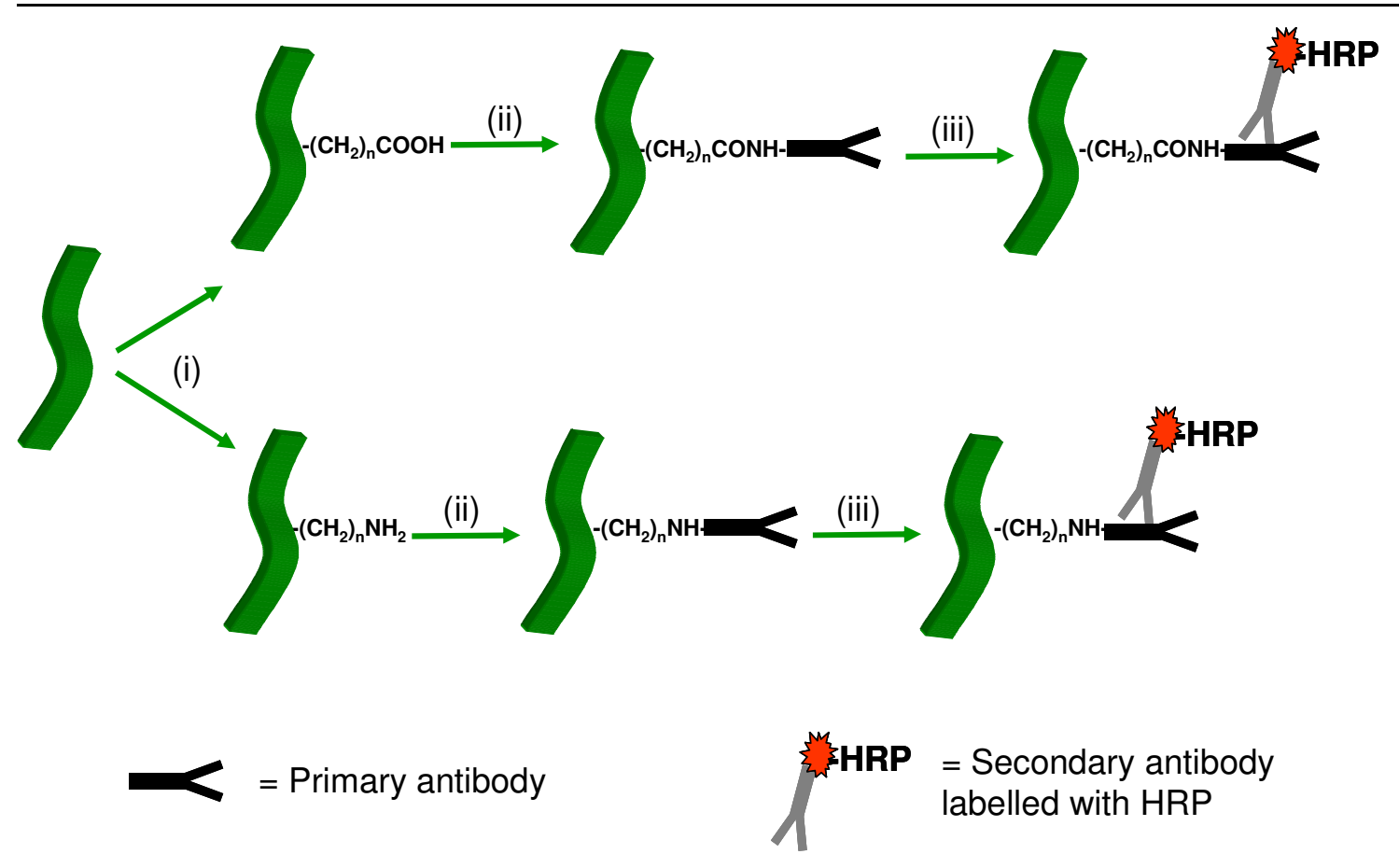

Scheme 1. 


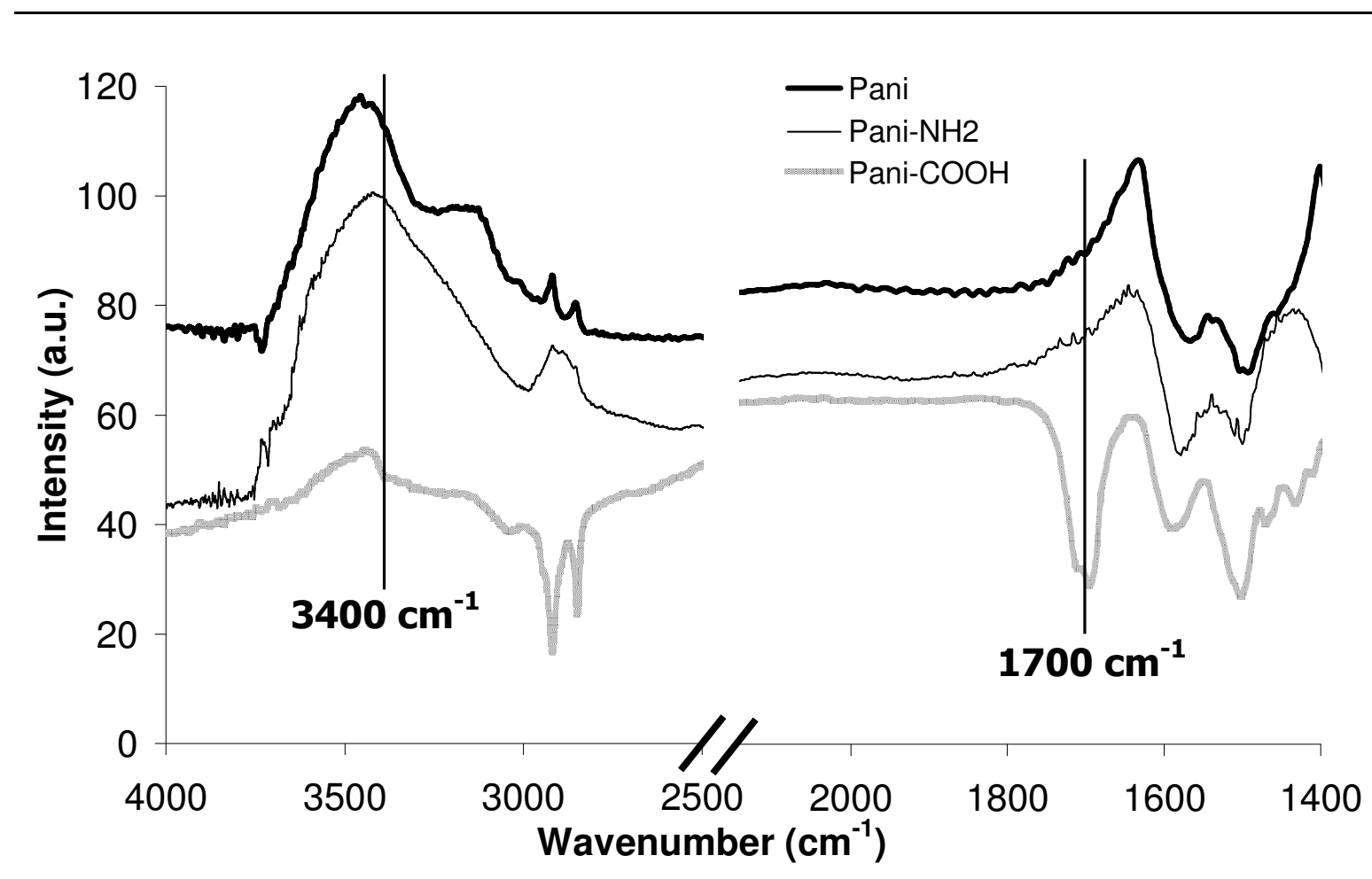

Figure 1.
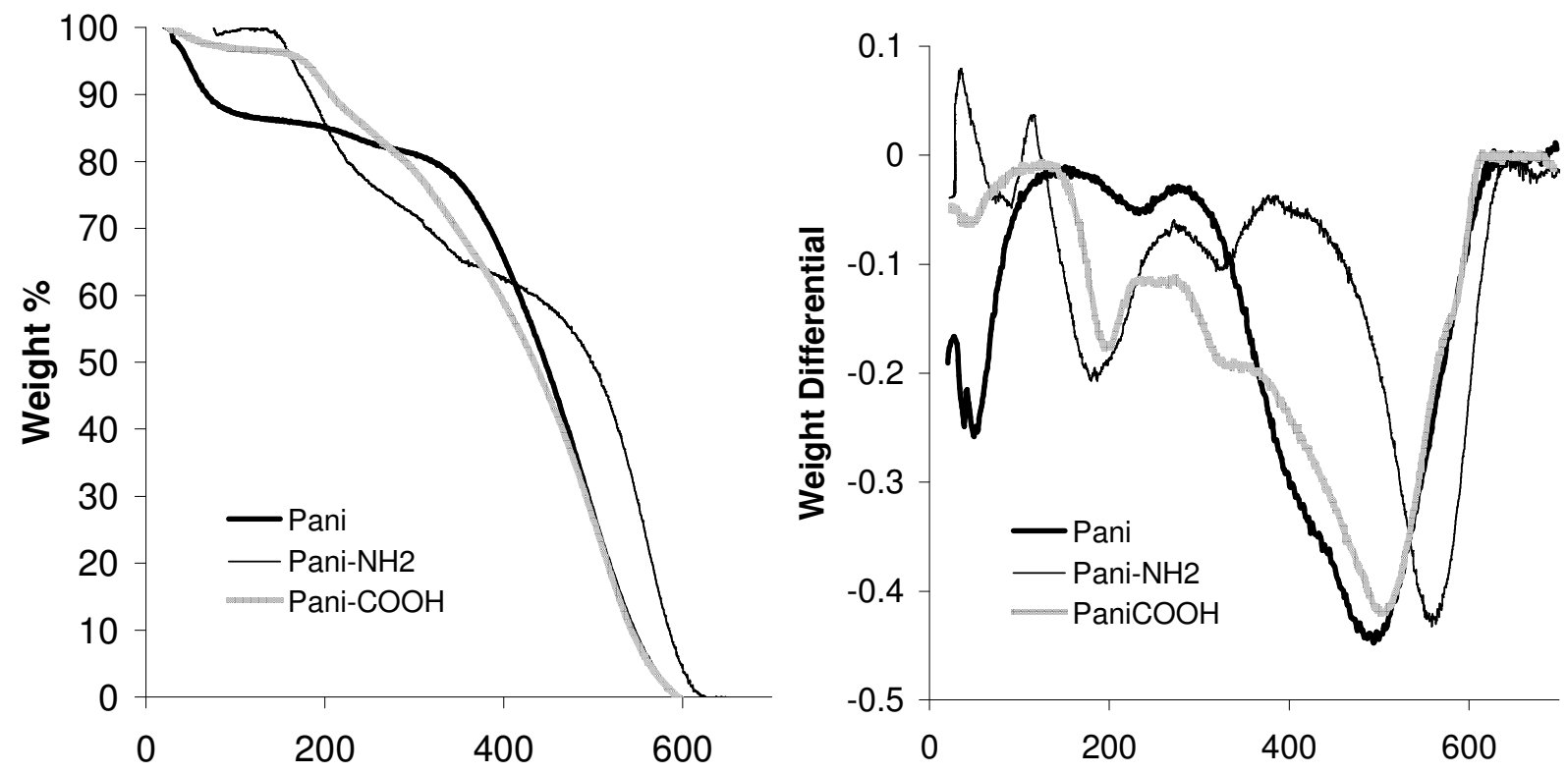

Figure 2. 


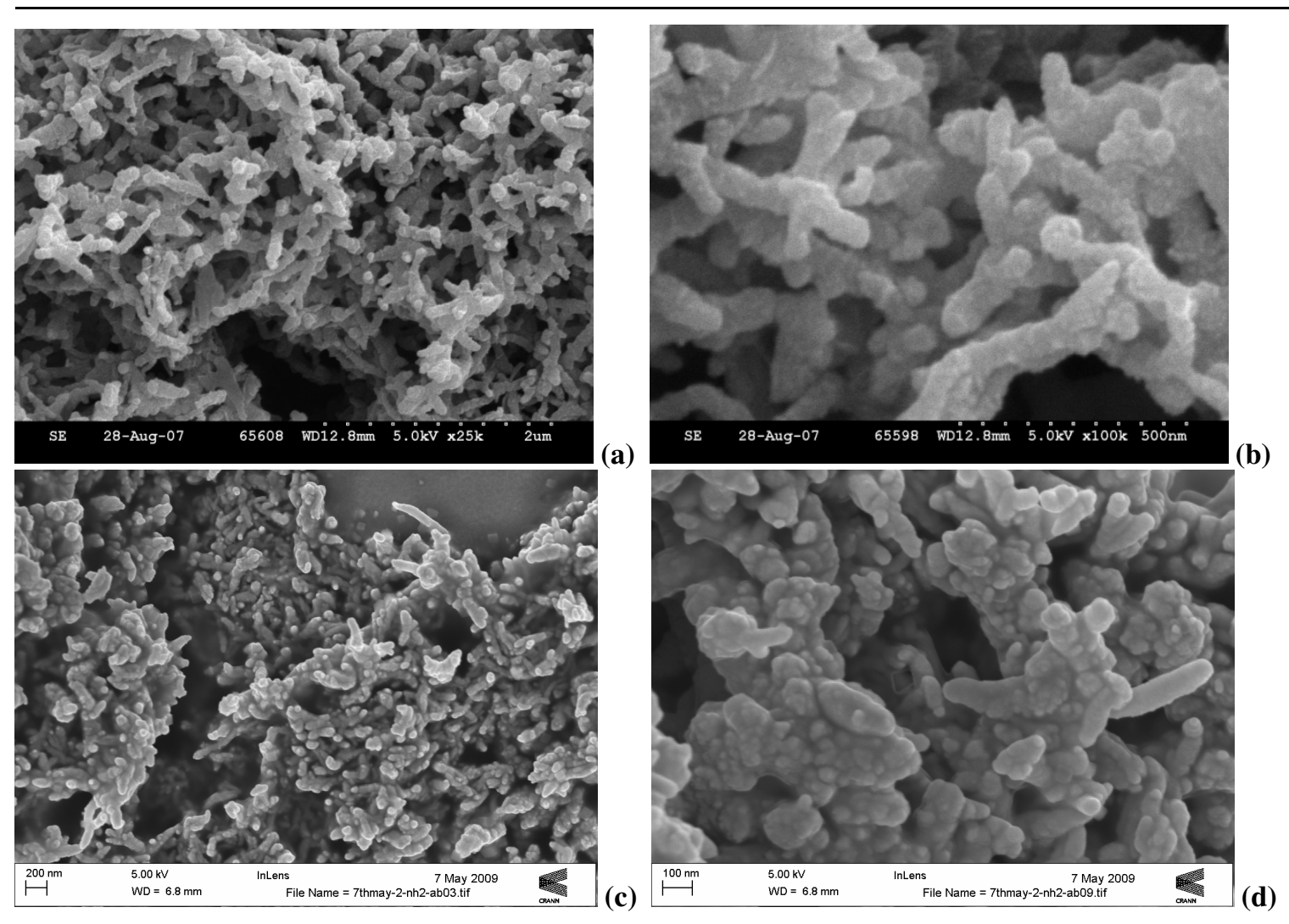

Figure 3. 

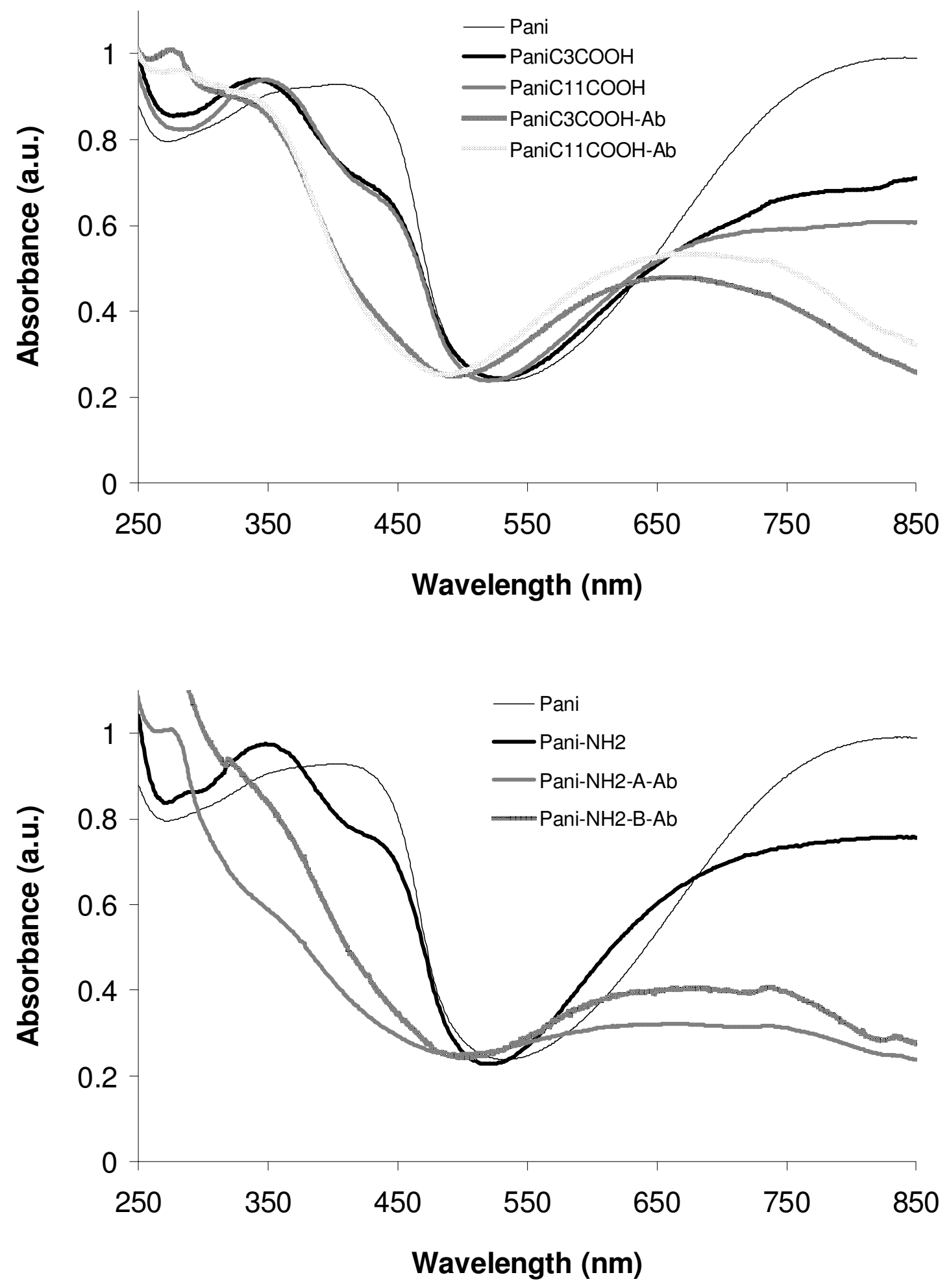

Figure 4. 


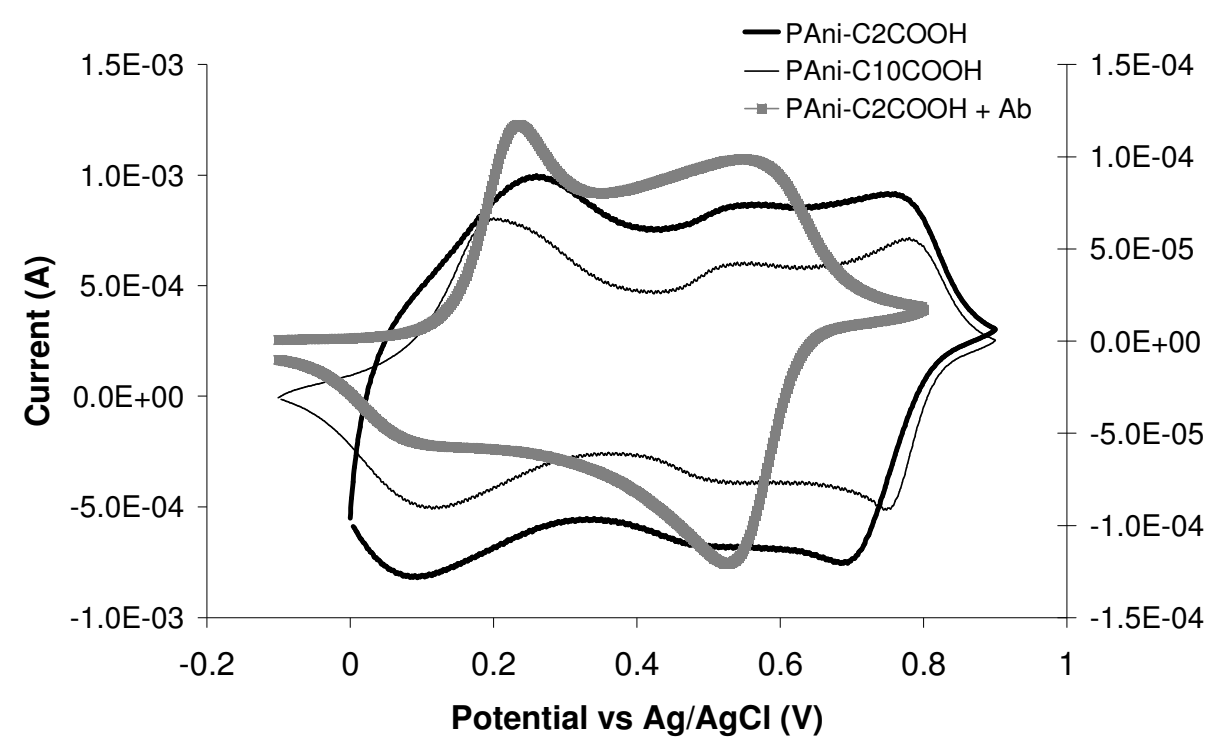

(a)

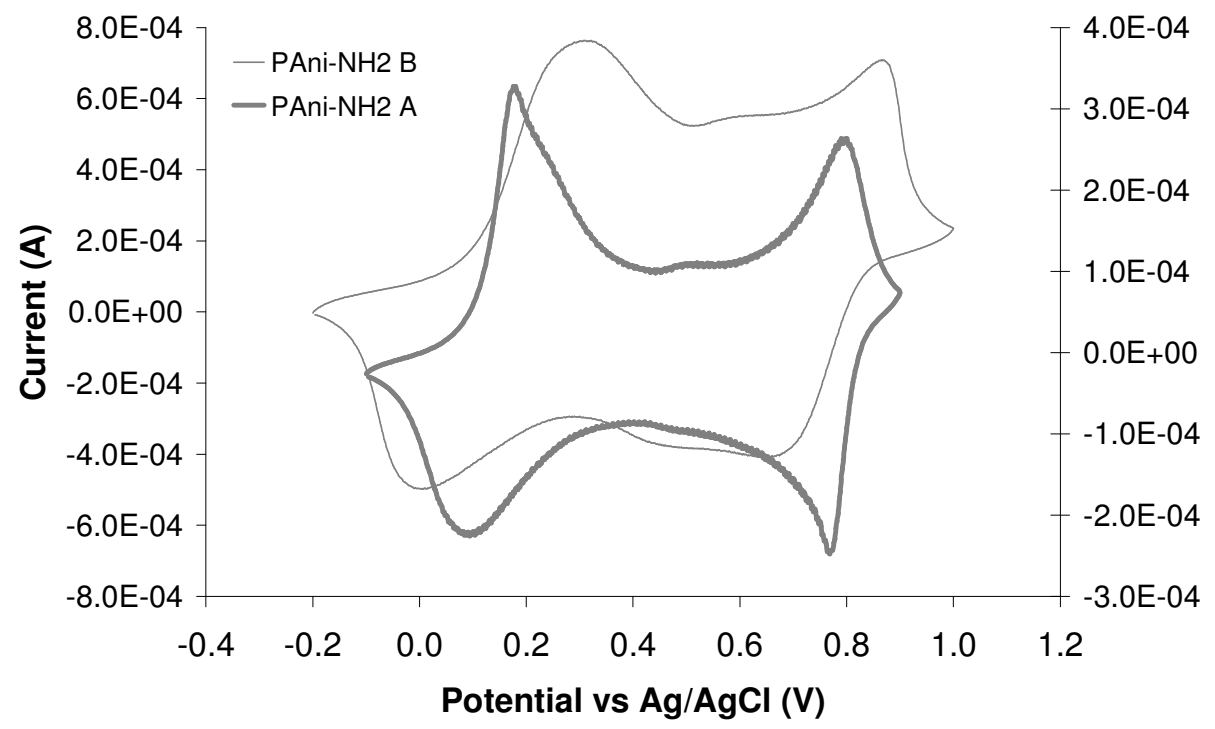

(b)

Figure 5. 


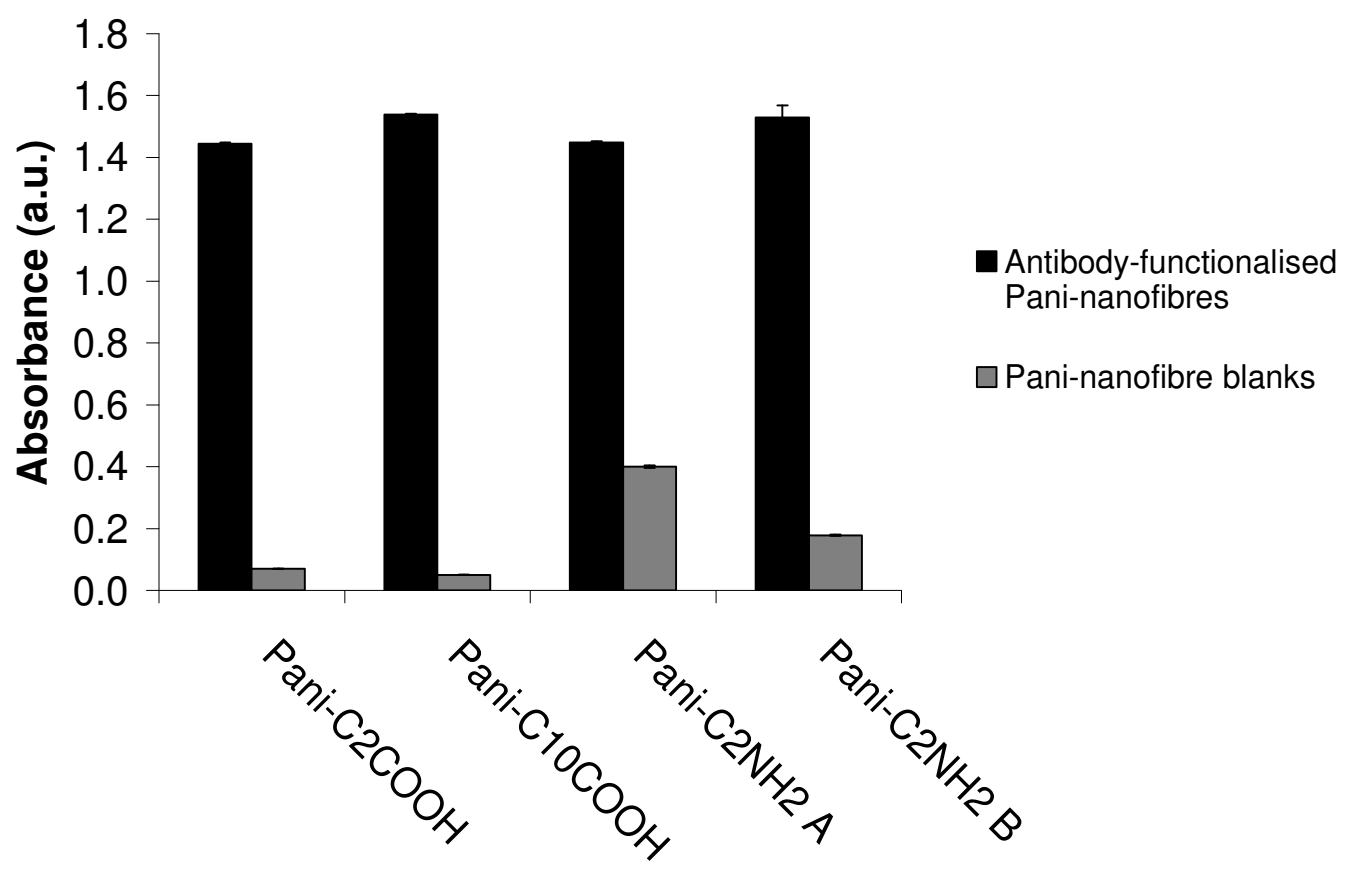

Figure 6. 

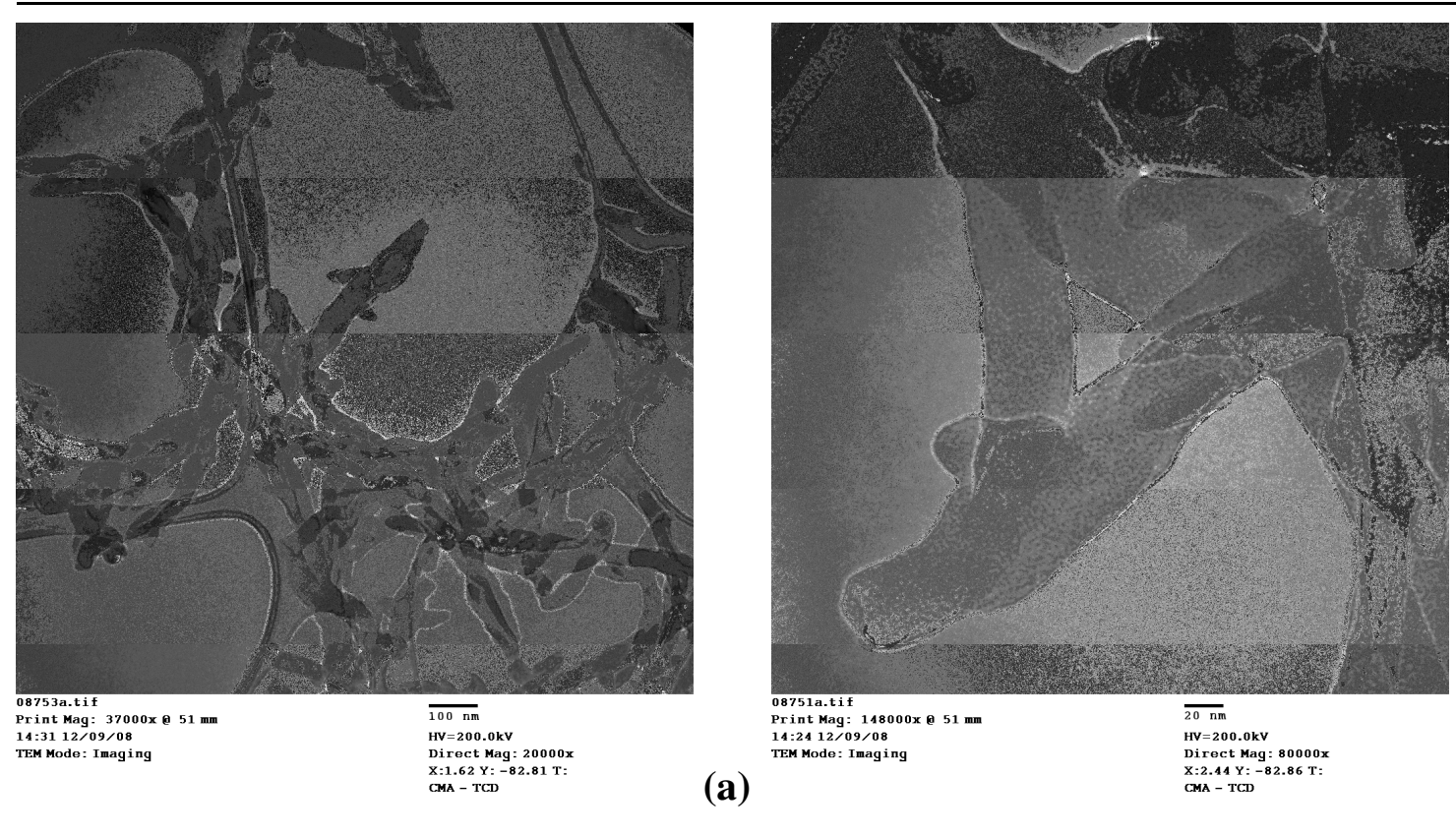

(a)

Direct Mag: $80000 x$
$X: 2.44 Y:-82.86$
$T$ :

(b)
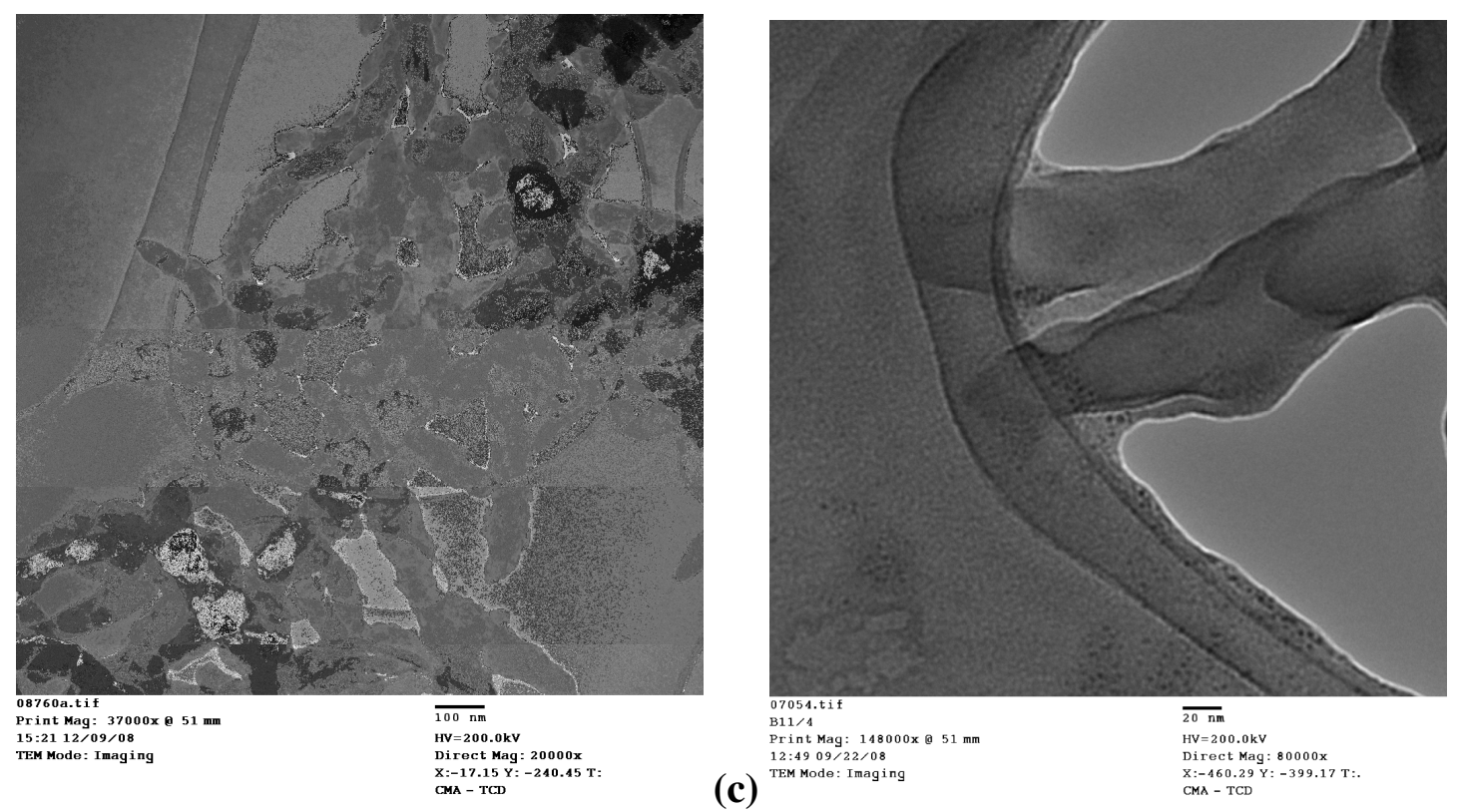

(d)

Figure 7. 


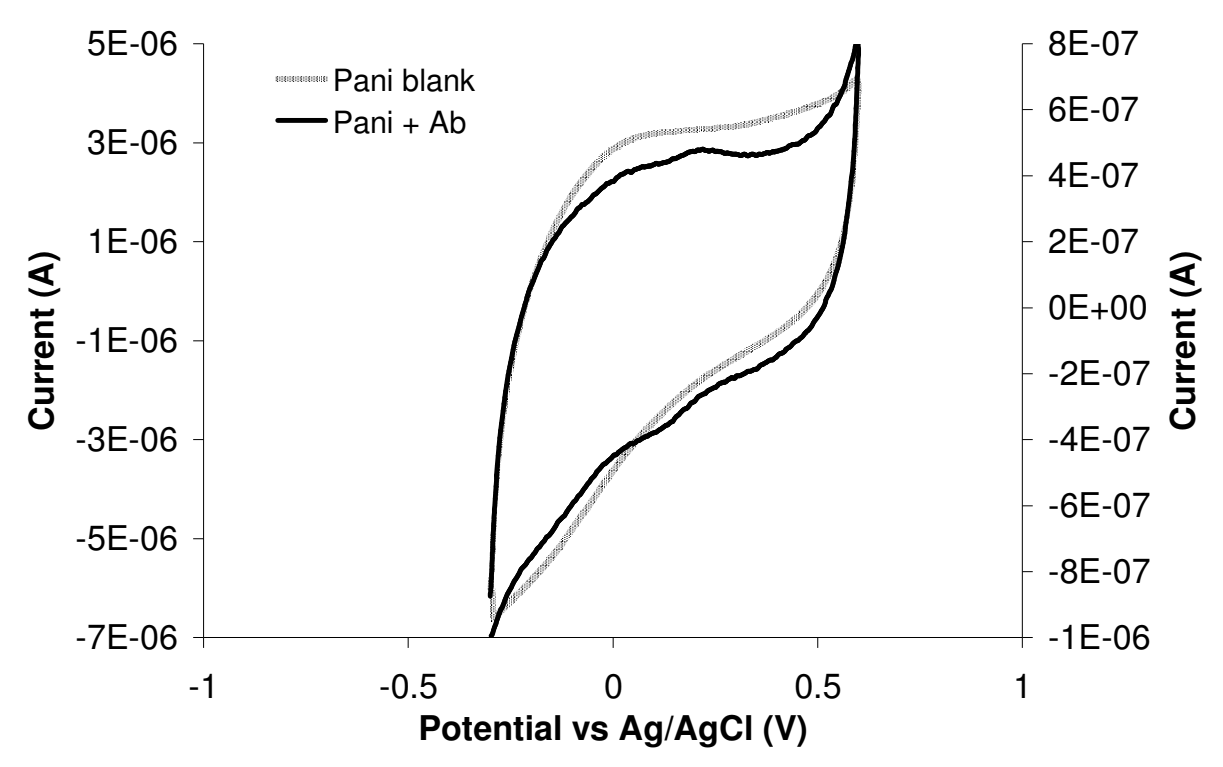

Figure 8. 